\title{
1. Introduction: hydrocarbon culture amidst a changing climate
}

All but one of the chapters of this book, the concluding one, are devoted to the problems arising from the entanglement of fossil energy and political power in Russia. I argue that this is essential, as we cannot come up with any positive and enlightened foresights for Russia and its partners without a very detailed knowledge of the problems in the current energy-political system and its specific hydrocarbon culture mentality. The hydrocarbon-dependent regime of President Putin is both unable and unwilling to see the inevitable systemic change that is approaching, and brought about by global climate change. This Russian deadlock has encouraged me to seek tools to confront the problem. I define the task in this chapter by outlining the aims and scope of the book. The latter part of the chapter contextualizes Russian energy: it is devoted to Russia's energy resources, their extraction, domestic use and export, and also defines the central actors determining the main directions of Russia's energy policies, which includes paving the way towards much-needed climate neutrality.

\section{RESOURCE GEOGRAPHY SETS THE SCENE FOR POLITICAL CULTURE}

This book is an attempt to understand how natural resources and energy affect the political aims, societal discourses and cultural identity of the Russian society. Furthermore, it aims to analyse how different energy sources set conditions for specific political and cultural practices that frame Russia's choices, and what the consequences of this are for Russia and the global community. The focus is more on discourses and practices promoted by the elite rather than the popular embrace of that agenda. The fact that high dependence on oil and gas is justified by the economic and political elite via space and time - oil and gas are depicted as part of Russian identity and justified with the help of geography and history - is at the epicentre of the analysis. 
On the one hand, the book is linked to debates over the societal and political implications of energy, and especially that of energy dependence. Thus, readers will find connections to the academic discourse of the resource curse, for example, a discussion linking the research interests of economists and political scientists in a quest to understand the economic and political implications of high resource rents and economic dependence on one or a few (energy) resources. In addition, the concepts of 'energy superpower' and 'energy weapon' are referred to in the book, but the links between energy power and energy security are examined with a twist differing from the traditional accounts that dwell on the topic of energy as political leverage. Due to the theoretical and methodological choices I make, which echo my understanding as a political geographer of what is interesting and relevant, I emphasize that the spatialities and materialities of energy do play a significant role in explaining Russia's choices. The point of departure is that energy materialities possess agency that frames policies and practices, narratives and discourses by limiting or enabling different actors to exert power. This means that the power of various energy sources and the materialities linked to them, such as oil geology and geography, pipeline infrastructure, a district heating network or the heat produced by gas, set conditions for certain political, bureaucratic, commercial and cultural practices in the society. Due to their spatiality and the materialities - the environment, geology, infrastructures, flows, links, networks and rents related and connected to oil and gas - hydrocarbon energy has a conditionalizing effect on societal development, especially in the Russia context. The fact that geography and history frame Russia's choices (Lo 2015) is amplified via the high dependence on oil and gas, which are once again being depicted as part of Russian history and geography. Thus, the agency and power of Russian energy is approached with a viewpoint where Foucauldian power-analytics and Latourian actor-network theory meet a spatially thinking scholar.

One presupposition I make in this book is that Russia is a nation and a country impacted negatively by a high dependence on energy rents and flows. Russia is not cursed on the same scale as Saudi Arabia, Turkmenistan or Venezuela, but much more than the United States or Norway, which are also major energy players. Thus, in econometric terms Russia's dependence is a hybrid falling somewhere between these two groups of oil and gas producers. Before the drop in global oil prices that began in 2014, the income from oil and gas exports covered a little more than half of the government budget (Sabitova and Shavaleyeva 2015). Approximately two-thirds of this - one-third of total budget income - comes from oil, because Russia exports 75 per cent of the 550 million tons of 
the oil that it produces to other countries as crude oil (50 per cent) and refined oil products ( 25 per cent). In contrast, nearly three-quarters of the 650 billion cubic metres of gas produced is consumed in Russia, so it only provides approximately 15-20 per cent of budget income flow. These flows of energy within Russia and especially out to the global markets mean that Russia's energy industry accounts for 25-30 per cent of GDP. These indicators show that Russia is highly, but not chronically dependent on fossil energy rents. As these countries grow more dependent on oil and gas, they become more authoritarian, have weaker (official) institutions, and lag behind others economically (Överland et al. 2010).

My aim is to take this fossil energy dependence as a contextual factor that makes many political, societal and cultural discourses and practices understandable. Therefore, the analysis I carry out provides a more profound explanation of the societal and political effects of energy dependence: my arguments utilize empirical studies focusing on the spatialities and materialities of how energy power is practised in Russia. Naturally, the materialities of energy and the assemblages formed around fossil energies do not dictate decisions, narratives, deeds or words vis-à-vis the central energy, environmental, social and foreign policies of Russia. They frame them to the extent that some powerful actors and institutions, such as the state-owned gas giant Gazprom, may use these spatialities and materialities to foster power strategies that benefit these actors. However, at the same time, these very materialities enable resistance by helping to construct and maintain counter-discourses and practices that challenge the (statist) hegemonic discourses and practices. Here also lies the potential for change: the path dependency that creates the spatialities and materialities of fossil energy also helps us to understand what is needed to build a new more sustainable society that draws its power from different spatialities and materialities. Furthermore, energy spatialities and materialities also possess agency with a power of its own that nobody controls. This agency comes close to infrastructural inertia, but is actually a much wider notion: the agency of energy and its materialities are the product of material and human, infrastructural and social, technical and cultural elements. I study this intertwinement using a power-conscious spatial approach, by asking explicitly how the spatialities and materialities of fossil energy are used as part of a political technology or political power in the Russian context, and how this path dependence can be broken.

Historically speaking, from Siberian fur in the sixteenth and seventeenth century to Siberian, Arctic and Far Eastern oil, gas and uranium in 
the twenty-first century, Russia has always been socially and economically dependent on the extraction of natural resources and production of raw materials. In that respect, one can argue that natural resources, and even today, energy have always been part of the formula that explains the framework and scope of politics and policies in Russia. The argument I make here is that Russia's high societal dependence on the extraction of natural resources impacts not only politics and policy but also the polity (e.g. Ferguson and Mansbach 1996). Polity refers to the whole spectrum of how the society is governed and ruled, including how it is kept intact discursively. A polity is made up of 'identity', 'resources' and 'hierarchy', which are factors that explain and justify each other. Identity is linked to the (natural) resources that are, again, linked to the way the society is governed. This is the situation everywhere concerning any nation or state: the environment and its resources do effect the identities of that particular culture. However, the fact that Russian society has always been governed in a hierarchical top-down fashion by tsars, general secretaries and presidents, who exert their personal power and that of the elite over the people in a non-democratic way, urges us to ponder more thoroughly the link between identity, rule and resources. In this book, I argue that the high dependence on natural resources and - in the case of Putin's Russia - energy encourages a more authoritarian rule than what would have been the case with a different view of resource geographies and the economic strategies utilizing those geographically versatile resources. Thus, the geographies of natural resources and histories related to their extraction play a pivotal role. The fact that the main stock of natural resources - from furs to timber and coal and from hydrocarbons to uranium and diamonds - has historically been located in the periphery and thus spatially detached from the main bulk of population and from central settlements and cities in the core areas is the key to understanding the form of rule that has developed in Russia. The rulers have never really been dependent on people as resources, but on natural resources that have been and are detached from communities and the people. Thus, my argument is that geography has played a significant role in framing how the country has been governed - and it continues to do so.

Thinking of the polity formed over centuries in the territory we know as today's Russia, another concept - namely Great Power or Empire - is closely linked to the discussions on polity and of paramount importance. I argue that in the Russian case, the empire rather than the state is the territorial manifestation of a polity. The territories of an empire are not strictly defined and fixed, as with Westphalian states, which leads to a fluid body politic and, thus, implicitly to unpredictable behaviour. 
Political scientists who focus on Russia and politicians and diplomats who know Russia tend to agree only about this: Russia has been and remains unpredictable. Approaching this discussion with a spatially schooled mind inspires the following question: is Russia as a nation and as a polity doomed by its geography? Is it doomed to authoritarian rule and poor governance, unpredictability and, subsequently, violence towards its own people and the outside world because of this built-in unpredictability, and therefore seen as a pariah state among the nations of the world? The economic and political trends of post-Soviet Russia unfortunately strengthen this gloomy prediction (for example, Gel'man 2015; Gessen 2017). The role of natural resources - especially fossil energy, oil and gas - has increased significantly since the last Soviet decade: in the 1980s the GDP share of the energy sector was about 10 per cent, whereas during the 2010s it is around 25 per cent (Simola and Solanko 2017). The energy sector did not dominate the Soviet economy, but it does dominate Russia's. In addition to arms, energy and raw materials are the only competitive Russian products in world markets. The recent increased inputs to the arms industry is the direct consequence of energy rents, oil and gas money, which are easily available to the regime and are also used to protect the regime against enemies - internal and external, real and imagined. I argue that the violence Russia has carried out is linked to the fact that the Putin regime feels threatened by internal and external actors - it either really thinks that it is a surrounded fortress that other groups and states want to conquer and destroy or it uses this narrative as clout to justify extreme measures that distract public attention from the real structural problems facing Russia (Gel'man 2015; Yablokov 2018). At the heart of this fear is the realization that the regime is in fact extremely weak, and its legitimacy constantly challenged first and foremost by the Russian people. A central issue being challenged by the population is the role of Russia as a mere producer of raw materials, 'an energy-producing appendage of the West' (Rutland 2015), as this is linked to the layman's experience of economic injustice prevailing between the elite and the people. Therefore, the increasingly central economic and political role played by hydrocarbons has to be justified to the Russians; and this must be done, as the future of the Putin regime itself is in many ways dependent on hydrocarbons. This has pushed the regime to build a legitimizing narrative around hydrocarbons, in addition to turning the focus from systemic economic and societal problems caused by the fossil energy dependence to producing conflicts on the international arena in hopes that the construction of an outside threat will unite the Russian people under the grand strategy. Thus, the violence Russia has practised 
and propelled in Ukraine and Syria, and the hostile actions towards its Western partners - from meddling in elections, mingling with and funding the far-right, performing 'covert' targeted military operations, hacking and trolling, and even running a state-led doping programme are all carried out in order to produce fault lines in Europe and America and to weaken the West. All this may seem like we are witnessing a strong Russia. However, what we really see is the fearful leadership of a 'Potemkin Empire', which understands that its power and legitimacy are actually built on very shaky ground.

During the Putin era and since 2000, economic affluence and wealth has also been increasingly concentrated in the hands of a shrinking group of people. Today, three-quarters of the wealth in Russia is owned by 1 per cent of the population, or approximately 1.5 million people. In comparison, this figure is less than 40 per cent in the United States and China (Shorrocks et al. 2016). The ability to accumulate wealth within networks of power may seem like an outcome of deliberate decisions. However, the ability to do so is also linked to the specific geographies of energy. Since the number of people employed in the oil and gas sectors in Russia is relatively low, despite the fact that companies such as Gazprom are among Russia's biggest individual employers, the workforce in the oil and gas sector has poor bargaining power. The silence of the few people needed to keep the hydrocarbons flowing from the wells to households, power plants and export can easily be 'bought' and tamed, without the need for the regime to submit to labour's political agenda. Timothy Mitchell (2011) describes this paramount change in labour bargaining power when the global energy transition pushed us away from dependence on coal, and married us to oil and gas. People employed in the coal industry were a political body that had a democratizing effect in Western industrializing countries: the labour unions would not have been strong without the bargaining power of the coal workers, who were in a position to halt industrial production dependent on coal via strikes and blockades, thus providing leverage in relation to how capitalists and political elites could accumulate wealth and power. This leverage potential existed during the Soviet economy, as coal and steel industries were economically pivotal in addition to being major employers. Of course, this leverage position can easily be contested by arguing that the totalitarian nature of the Soviet state did not allow this position for the workers. We know that the labour unions of the Soviet Union were de facto weak (Blom et al. 1996). The labour unions provide some social stability in today's Russia, but remain as weak as during the planned economy. Moreover, the most lucrative and thus important sector of the Russian economy - oil and gas industries - is a good employer with high salaries, but oil and gas 
workers have poor political leverage. It accounts for a meagre 1-2 per cent of the overall workforce, depending on the definition (Simola and Solanko 2017). The fact that oil and gas are produced in areas with extremely low population densities, detached from settlements and the densely populated European Russia, further enables the Putin regime and its closest entourage to keep the main rents and networks of power in their hands. The geographies of natural resources and those of fossil energy thus allow the Russian leadership to carry out policies that serve their interests and consolidate power via two factors that reinforce each other. First of all, the sector that produces rents and enables power within Putin's entourage is (socio-)politically weak due to the low number of people employed in that sector, and therefore easily controlled and tamed. Second, the production and transportation - and to lesser degree refining - of oil and gas take place in spatially extremely confined points and corridors in the territory of Russia, detached from the lives of most Russians, which means that extracting those resources does not expose the Putin regime to any serious conflicts with the local communities and Russian society.

In summary, oil and gas both make it possible for and push Putin's regime to be violent towards its own people and pay little attention to international norms - from respecting the sovereignty of other states to promoting global efforts to mitigate global climate change. I emphasize that a Russian Empire that is less dependent on hydrocarbons or similar resources that centralize power could still be an unpredictable and violent actor. However, I argue that the likelihood of this is significantly lower in an energy and resource-wise decentralized, economically regionalized and politically federalized Russia than under the contemporary hydrocarbon-based rule. Next, I will discuss the premises for moving away from that diabolical hydrocarbon dependence.

\section{RESOURCES FOR ENERGY TRANSITION?}

Russia is an energy giant - and this concerns hydrocarbons, coal and uranium as well as renewable energy. In addition, Russia has the technologically relatively developed society needed to foster an energy transition towards a low-carbon economy. Russia has a large bioenergy potential via its forests, which are the largest in the world, but its extensive territory also provides the potential to develop wind, smallscale hydro, solar and geothermal power in an economically viable way. Despite this promising premise, a more accurate glance reveals that high dependence on extraction of natural resources, which defines the Russian 
economy and politics, is an aspect hindering the transition towards carbon neutrality and renewable energy. The most crucial factor defining energy governance in Russia is the fact that its territory is endowed with large deposits of oil, gas, coal and uranium. Especially, the pivotal role played by oil and gas industries in the Russian economy and the strong linkages between political power and the fossil energy sector seem to be at odds with the energy transition objectives also set in Russian governmental strategies since the early 2000s. The energy sector covers roughly a quarter of national GDP and the export of oil and gas alone contributes from one-third to half, depending on the price of oil, to the Russian state budget revenues (Simola and Solanko 2017). In this situation, determined by the realities of Russia's political economy, it is therefore hard to set an unbiased playing ground for those industries and actors making it possible to pave the way for energy transition towards a low-carbon society.

An abundance of energy and resource coupled with historical paths has created immense industries in all non-renewable energy sectors in Russia. The colossal size of the industries and companies in the natural resource sector is the result not only of political history and large resources per se, but also of particular resource geographies: the globally salient deposits of hydrocarbons, coal and uranium are not evenly distributed in the Russian Eurasian space, but concentrated in specific areas that are mostly far away from the population centres. As a result, the oil, gas, coal and uranium industries have required major infrastructural investments in order to develop resources found mainly in the periphery. The fact that gas industry leader Gazprom controls 40000 kilometres of gas pipelines is thus the outcome of the political economy history in Russia, as well as the distinct population and resource geographies of a country with the propensity to 'stretch' these infrastructures. This feature then magnifies the energy-society loop: the more Russia has been forced to invest in energy infrastructures (such as gas pipelines, oil ports, etc.) to maintain production volumes that allow a particular level of rents, the more its political choices have been decreased concerning the energy transition from a carbon-based to a carbon-free energy system.

Energy efficiency objectives promote, at least on the discursive level, the introduction of renewable energy sources (RES) because renewables are also seen as a substitute, especially for oil and coal in the domestic energy mix. Nonetheless, this goal seems very difficult to attain, despite the fact that the legislative base to invest in renewable energy projects has been laid, and there are a few cases of recent successful RES projects. Russia has all the material resources to become a 'Green Giant', but at the moment it is severely falling behind all other major energy powers - 
the EU, China and the United States - in RES deployment. Lastly, the proportional increases in RES utilization may encourage the idea that a major transition is already underway in Russia, but this is only due to the exceptionally low starting point of RES utilized in Russia.

\section{THE 'ENERGY MIX' TODAY}

Russia is a significant energy exporter and rents obtained from exports of oil, gas, coal, uranium and nuclear technologies constitute about half of Russia's budget revenues, in addition to which the energy sector produces about a quarter of Russia's GDP. Around half of the energy produced in Russia is consumed in the country, which means 730 million tons of oil equivalent (toe), out of 1370 toe total. Since the 1970 s, the share of natural gas has increased significantly in the energy mix, and today it accounts for half of the overall energy consumption in Russia. Oil covers around one-fifth of Russia's energy demand, coal a little less than 20 per cent, and nuclear 6 per cent. Hydropower and renewables both cover between 1 and 2 per cent of the total energy demand, but hydropower and nuclear power cover one-third of electricity production in Russia, with each accounting for 15 per cent. Gas dominates electricity production with a share of almost 50 per cent, although its role has diminished during the last decade, whereas nuclear, coal and hydropower each constitute about one-sixth of the electricity produced in Russia (Table 1.1).

The transition from heavy oil and coal to gas in heat and power generation is a paramount systemic change in the energy sector of Russia. This change is pivotal not only due to its positive local and global environmental impacts - gas consumption releases far less pollutants affecting human health and ecosystems on a local $\left(\mathrm{SO}_{2}, \mathrm{NO}_{\mathrm{X}}\right.$, soot, etc.) as well as global $\left(\mathrm{CO}_{2}\right)$ level than oil and coal - but also concerning the role of players in the field of energy markets and policy. The gas sector is consequently central in all energy policy fields in Russia: gas covers half of overall energy consumption and along with electricity production, households are very dependent on gas indirectly via district heating and directly because gas is extensively used in cooking. 
Table 1.1 Total primary energy supply (TPES) in Russia (IEA 2018b)

Essential energy data, 2016
Total energy production: 1373.7 Mtoe (natural gas $39.2 \%$, oil $40.0 \%$,
coal $15.2 \%$, nuclear $3.8 \%$, hydro $1.2 \%$, biofuels and waste $0.6 \%$,
$+29.5 \%$ since 2002
TPES: 732.4 Mtoe (natural gas $50.7 \%$, oil $23.7 \%$, coal $15.5 \%$,
nuclear $7.0 \%$, hydro $2.2 \%$, biofuels and waste $1.1 \%$ ), $+18.4 \%$ since
2002
Electricity generation: 1088.9 TWh (natural gas $47.9 \%$, nuclear
$18.1 \%$, coal $15.7 \%$, hydro $17.0 \%$, oil $1.0 \%$, biofuels and waste $0.2 \%$,
geothermal $0.1 \%$ ), $+21.6 \%$ since 2002
TPES per capita: 5.2 toe, $+21.4 \%$ since 2002
TPES per real GDP: 0.34 toe/USD 1000 GDP PPP, $-23.6 \%$ since
2002

Nonetheless, there are significant regional differences in the energy mix, with the European part of Russia, excluding the High North, depending on gas, nuclear and hydropower, whereas Siberian Russia, especially the Far East, still relies on coal as the main energy source, although central Siberian industrial cities have evolved around massive hydropower plants that function as the primary source of energy for the heavy industries in these centres (Novosibirsk, Krasnoyarsk, Irkutsk, etc.). High reliance on coal, especially in the Russian Far East affects regional and even foreign policy considerations in the Kremlin. Thus, the national gas distribution programme, Gazifikatsiya Rossii (see Chapter 3), is carried out not only to raise gas coverage in the peripheral parts of European Russia and decrease the high level of energy poverty in these locations, but also to connect Siberian and Far Eastern regions and population centres to 'mainland' Russia. This connectivity is vital both in maintaining central control over these far-away regions, and subsequently impeding Chinese influence in this region that Moscow views with a geopolitical glance: as a potentially separatist region (cf. Wengle 2015, p. 10).

Wood has traditionally been the main source of energy in many Russian peripheral settlements in the countryside, as well as the source of energy and raw material for the Russian forestry industry mainly located in the Northwest and in Southern Siberia. Russia's overall capacity in renewable energy is vast, but less than 1 per cent of its total primary energy production is based on renewables (see Table 1.1). However, when measured in terms of what is economically viable with today's 
prices and technology, Russia could produce one-third of its domestic primary energy with renewables (Shuiskii et al. 2010, p. 325). In addition, more ambitious policies would allow renewables to cover all electricity demand in Russia (Bogdanov and Breyer 2015).

\section{EXPORTING A BEAR'S SHARE}

Russia exports roughly half of its energy production, 640 million tons out of 1370 million tons produced yearly. European Union countries are still by far the biggest buyers of Russian energy, but flows to China are increasing. The EU member states buy approximately 60 per cent, or 330 million tons, of oil produced by Russia, which is equivalent to threequarters of the oil exported by Russia. Although oil is economically the most important commodity between the parties, trade issues and especially disputes over gas dominate the headlines. Russia produces approximately 600 billion cubic metres $(\mathrm{bcm})$ of gas, but unlike oil most of it nearly 70 per cent - is consumed in Russia. Gas is the most important energy commodity within Russia, and also the most power-vested in terms of both domestic and foreign policy. The EU countries import approximately $200 \mathrm{bcm}$ of gas from Russia, accounting for one-third of all Russian gas production. Almost all gas flows to Europe via a few major and politically debated pipelines: old pipes traversing Ukraine, Belarus, Poland and other Central European countries, and the new Nord Stream I and in all likelihood also the twin pipeline Nord Stream II in the near future. In combination, they move up to $110 \mathrm{bcm}$ of gas along the bottom of the Baltic Sea from Russia to Germany, and from there on to European markets. In the future, the Russian gas companies Gazprom and Novatek also aim to export gas to European and world markets in liquefied form, LNG.

In addition to exports of hydrocarbons - oil and gas, as well as refined products from oil, gas condensates and gas - Russia is a major provider of coal and uranium. Again, the EU market is the primary destination for Russia's coal and uranium. Russia produces approximately 300 million tons of coal annually and one-third of this, or 100 million tons (in energy content this is equivalent to $70 \mathrm{Mtoe})$, is bought by EU countries. The volume $(2150 \mathrm{t})$ and share (15 per cent) of uranium of Russian origin feeding European nuclear power plants, some of which are Soviet/ Russian design, is also significant (WNA 2016). In terms of importing energy to the EU space, Russia provides approximately one-third of all imported fossil energy sources - oil, gas and coal - in all the sectors, and 
one-sixth of all uranium. All in all, Russia is a pivotal provider of energy to the European markets, and an emerging seller of energy to China.

As discussed above, domestic consumption of renewable energy in Russia has not evolved remarkably. However, real competition for Russian renewable energy might develop in a decade or two. For example, about 80-90 per cent of bioenergy produced in Russia is currently exported. By far the biggest importer thus far has been Sweden, where a large number of private households rely on pellets for heat production. Finland, Germany, the Netherlands, Denmark and Italy have emerged as important buyers of Russian bioenergy (Aguilar et al. 2011, p. 90). For Russia, it would make sense to export those forms of renewable energy that are exportable, mainly bioenergy, and proceed in replacing domestic fossil fuel consumption with non-exportable renewable energy and with hydro and nuclear power. The fact that the EU is moving fast in the renewables sector and that Russia seemingly plans to rely more on renewables only after 2020 (Ministry of Energy RF 2009, p. 23) creates a win-win situation for these energy partners, especially with consideration to the next decade or two. The Energy Roadmap 2050 (European Commission 2011a), which was formulated between the two parties and in the framework of the EU-Russia Energy Dialogue (European Commission 2011b), clearly states that Russia could become a source of both renewable electricity and bioenergy imports for EU countries.

\section{INSTITUTIONAL ACTORS ON THE ENERGY SCENE}

The official agencies in control of energy issues within the Russian state administration are the Ministry of Energy (min-energo-gov.ru) and the Ministry of Natural Resources and the Environment (mnr.gov.ru). The former outlines Russia's energy policy, such as the Energy Strategy of Russia (Ministry of Energy RF 2009, 2017), whereas the latter has the mandate to issue licences for new energy developments, for example, granting rights concerning which enterprises can access which energy deposits. The President and the Presidential Administration (en.kremlin.ru/structure/administration) do not have a separate organ focusing on energy issues and policy, yet the President has legislative powers through decrees (ukaz) that also apply to the energy sector. However, the President has straightforward leverage on the decisionmaking of the three state-owned energy companies, Gazprom, Rosneft and Rosatom - all of which are central actors in terms of defining energy policies in Russia. 
Gazprom is an open joint-stock company (OAO) in which the Russian state has owned 50 per cent plus one share since 2005. It is the successor to the Soviet Ministry of Gas Industry and at the moment employs more than 450000 workers, produces 70 per cent of Russia's gas and also includes finance and media in its portfolio. Despite the fact that Gazprom is a commercial enterprise and not a state corporation, it can be defined as a parastatal company. Naming it as a parastatal company implies that the Russian state and President Putin's regime exercise authority over the decisions of the enterprise to a greater extent than its legal position as a commercial enterprise would allow. Naturally, not all the decisions of the enterprise are politically motivated, as business rationale is the main motivation for operational decisions taken by the company. Moreover, Gazprom is a vast company that includes dozens of regional subsidiaries with objectives and political voices stemming from the realities of the Russian regions. That said, all strategic moves, especially concerning overseas operations and major infrastructure projects, are decided by Putin's entourage. Since the company is controlled by Russia's political elite, it has more privileges and also more state-defined societal tasks than any other enterprise in Russia. In the 2010s, Gazprom lost its monopoly over gas exports and had to grant other companies, primarily Novatek, Rosneft and Lukoil, access to the domestic gas pipeline system. However, the monopoly still predominates in practice despite the fact that more competition is now allowed. This position has allowed it to diminish competitors' opportunities to increase their market share in regional energy mixes or the national gas market. This makes Gazprom's position in the Russian domestic energy sector an exceptional one: it has the power to block renewable energy and coal producers who have prospects to increase their production in the Russian regions, as well as the ability to prevent oil companies from feeding associated petroleum gas into the national pipeline system (more on Gazprom in Chapter 3).

Rosneft is another state entity focusing primarily on oil production. It is the world's largest listed oil company by output and has a workforce of 250000 employees, bringing it close to Gazprom in terms of its role in the Russian economy and society. With 50 per cent state ownership, Rosneft can be similarly defined as a parastatal company, despite its substantial private and foreign ownership (BP and unknown offshore owners each hold 19 per cent). The national oil company, which is the successor to Mikhail Hodorkovsky's Yukos oil company that was taken over by the state in the early 2000 s, is to an increasing extent challenging Gazprom's monopoly in the gas sector and that of the second largest gas producer Novatek, which is privately owned but still controlled by people close to the president. Rosneft has a central role in the energy efficiency 
of oil production in Russia, which is a major contributor to the greenhouse gas (GHG) emissions and other environmental problems of the country. This is linked to the fact that Rosneft produces two-thirds of Russia's oil and also has the lowest energy efficiency in the oil sector. This is most pronounced when looking at the issue of burning of associated petroleum gas on the site of production, also known as APG flaring (see Chapter 5).

Russia's third major energy player is Rosatom, a state corporation that functions in the nuclear energy business in addition to producing nuclear weapons. According to Russian legislation, Rosatom, unlike Gazprom and Rosneft, has no obligation to produce an economic surplus. The nuclear giant is thus better resourced and positioned to promote energy and other policy objectives set by the state domestically and internationally. In Russia, nuclear power is prioritized in relation to renewable energy and coal, but not compared to gas, and internationally Rosatom is

able to compete and increase Russian influence through highly attractive nuclear power plant and uranium provision offers (see Chapter 4; Tynkkynen 2016c).

Naturally, a central actor is the Russian society at large. The authoritarian nature of the Putin regime means we cannot really talk about Russian civil society per se having a significant effect on policy formation or chosen policies - at least not in the way civil society actors in liberal democracies affect political life, for example, via representative (local, national elections) and more direct democracy (civic initiatives, lobbying and protesting, NGO activism). However, despite the fact that the political and economic elite of Russia enjoys far greater freedom than their counterparts in liberal democracies with regard to implementing energy policies based on their incumbent interests, there remains a need to justify the decisions and actions of the elite to the Russian people via practical and discursive means. This is shown in detail in the following chapters.

\section{THE VISION FOR A GREEN AND RESILIENT RUSSIA: CLIMATE CHANGES GEOGRAPHY, GEOGRAPHY CHANGES POLITY}

As outlined above, I intend to push the discourse on the entanglement of energy and power further by adopting a spatially conscious take on energy and power. By means of this theoretical and methodological choice, I argue that we can know more about Russia - a country, I claim, 
that can turn into a global vector for positive and sustainable development. Therefore, I want to use this book to engage in critical discussion about Russia's choices. I argue that Russia is suffering from a multitude of societal problems due to the intertwining of political power and fossil energy. Fossil energy, oil and gas, is not a competitive advantage for Russia on the global stage, and thus not a blessing for the Russian leadership and its people. My view of the current state of affairs concerning Russia, resources and energy is critical, but far from hopeless or nihilistic.

I will use empirical studies to not only show why the existing hydrocarbon-based system is a barrier to development in Russia and beyond, but also that Russia and the Russian people can choose differently and prosper. Hence, the book ends with a realistic vision of a future where the consequences of climate change and the economies that will flourish due to it, which seem so insignificant to many Russians and the Putin regime at the moment, will function like a game changer. I argue that despite the historical inertia of resource-led development and the authoritarian rule encouraged by it, Russia is not a prisoner of its own geography. More precisely, geography and resources are Russia's assets as they are anywhere else - but the challenge is to lean not on the most tempting and disastrous option, as is the case today with oil and gas, but on those riches that enable a resilient and sustainable Russia and a healthier planet. Unfortunately, this change will partly come about because of global environmental change and especially the adverse social and economic effects this change has on Russia. However, this 'stick' effect will be accompanied by a 'carrot' effect, and this is where Russia's potential as a 'Green Giant' or an Ecological Great Power plays a pivotal role.

Russia is also an energy giant in terms of renewable energy, and here Russia can play an important role in transforming its own energy system and drastically reduce its own emissions - Russia is currently the fourth largest emitter of GHG (Korppoo et al. 2015) - while also providing the means for others, namely China and Europe, to enable the switch from fossil-based energy systems to those relying on renewables. This systemic transition and political transformation has good potential to materialize, because it is well-suited to the socio-cultural and political self-understanding of Russians. Thus, I argue that Empire or seeing Russia as a Great Power which is a view shared by many in Russia, is an asset that can be used for the common good of Russians and humanity (see N. Tynkkynen 2010). In other words, this new role will suit the Russians very well, as it appeals to the national identity: the idea of a Great Power with a special global, even messianic, task has always been 
a central element in Russian political thought (e.g. Kivinen 2002). This means that Russia, along with other great powers, can be a key player in fostering the transition to a climate-neutral world. As climate change risk becomes reality and also because of its nature, Russia can enable positive change by promoting a new kind of energy policy. Russia can subsequently become a strong player, one that is resilient and sustainable both internally and externally. However, this requires that Russia and Russians re-evaluate their geography and the strengths it provides, which in turn entails profound changes in political priorities within the country. Encouraged but also pushed and forced by global environmental and economic changes, Russia is capable of drifting onto a positive development path where energy and natural resources continue to play a role. However, the profoundly different spatialities and materialities, geographies and infrastructures of renewable energies can help to guide this monolithically-ruled country onto the path of decentralization, regionalization and federalization. Here, the whole territory of Russia becomes an asset, as opposed to the minuscule points on the peripheral Siberian tundra where oil and gas are extracted today.

At the moment, a chronic dependence on fossil energy, hydrocarbons and a characteristic tendency to centralize and strengthen the hierarchy make Russia weak in terms of domestic and economic policy and subsequently an unpredictable and dangerous player in terms of foreign policy. The country dodges potential criticism of the chosen hydrocarbon culture and its economic rationale by raising nationalistic sentiments among Russians by waging war and carrying out mafia-inspired manoeuvres internationally. This social contract - the people are given bits of the wealth created via hydrocarbons while political citizenship is denied rests on the assumption that the fear of a foreign threat, either cultural (liberal values), economic (decarbonization) or geopolitical (military cooperation), unites Russians under the guise of hydrocarbon culture and Fortress Russia. The blueprint and potential for a new energy-political system and mentality - a nation and an economy that enables rather than discourages the global change to a sustainable future - is founded on the idea that Russia's geography and its central assets as well as cultural and political thought act as our guiding light. 